\title{
РЕАЛИЗАЦИЯ ПРОДУКЦИОННОГО ПОТЕНЦИАЛА СОРТОПОПУЛЯЦИЙ MEDICAGO VARIA MART. В РАЗЛИЧНЫХ ЭКОТОПАХ ЮГА СРЕДНЕРУССКОЙ ВОЗВЫШЕННОСТИ
}

\section{IMPLEMENTATION OF THE BIORESOURCE POTENTIAL OF SOME VARIETIES OF MEDICAGO VARIA MART. IN VARIOUS ECOTOPES OF THE SOUTH OF THE CENTRAL RUSSIAN UPLAND}

\author{
Ж.А. Бородаева, В.И. Чернявских \\ Zh.A. Borodaeva, V.I. Cherniavskih
}

\author{
Белгородский государственный национальный исследовательский университет, \\ Россия, 308015, Белгород, ул. Победы, 85 \\ Belgorod State University, \\ 85 Pobeda St, Belgorod, 308015, Russia \\ E-mail: borodaeva@bsu.edu.ru
}

\begin{abstract}
Аннотация
В период 2016-2018 гг. в экотопах юга Среднерусской возвышенности была исследована продуктивность различных популяций люцерны изменчивой (Medicago varia Mart.). Изучали селекционный материал, созданный на основе форм с высокой экспрессией $m f$-мутации в сравнении с исходной популяцией сортов, из которых проводили отбор мутантных форм. Сортопопуляции с высокой экспрессией $m f$-мутации проявляли свой потенциал высокой продуктивности надземной фитомассы только в условиях высокого плодородия почв и оптимальных условиях экотопов, наиболее благоприятных для роста и развития M. varia. При посеве в неблагоприятных условиях они снижали свою продуктивность по сравнению с исходными селекционными популяциями. В условиях экотопов полевых севооборотов с черноземной почвой продуктивность надземной фитомассы сортопопуляций $\mathrm{c}$ высокой экспрессией $m f$-мутации была значительно выше, чем у исходных сортов. Селекционные образцы с высокой экспрессией $m f$-мутации К-1/10 $m f$ и Б-86/3 $m f$ в экотопе полевого севооборота с черноземом типичным тяжелосуглинистым обеспечивали величину надземной фитомассы соответственно 1209.7 г / $\mathrm{M}^{2}$ и 1175.8 г / $\mathrm{M}^{2}$ а.с.в. В условиях экотопа луга наоборот - они уступали исходным сортам на 50 - 65 г/м² а.с.в. В условиях экотопа с песчаным чернозем выщелоченным существенных отличий между ними не выявлено.
\end{abstract}

Abstract

In the period 2016-2018. in the ecotopes of the South of the Central Russian Upland, the productivity of various populations of alfalfa $(M$. varia) was studied. Studied breeding material created on the basis of forms with high expression of mf-mutation in comparison with the initial population of varieties from which the selection of mutant forms was carried out. Populations with high expression of the mf mutation showed their potential for high productivity of aboveground phytomass only under conditions of high soil fertility and optimal ecotopic conditions, most favorable for the growth and development of M. varia. When sown in unfavorable conditions, they reduced their productivity in comparison with the original breeding populations. Under the conditions of ecotopes of field crop rotations with chernozem soil, the productivity of the aboveground phytomass of variety populations with high expression of the mf mutation was significantly higher than that of the original varieties. Selection samples with high expression of the $\mathrm{mf}$ mutation $\mathrm{K}-1 / 10 \mathrm{mf}$ and B-86/3 $\mathrm{mf}$ in the ecotope of field crop rotation with typical heavy loamy chernozem provided the aboveground phytomass of $1209.7 \mathrm{~g} / \mathrm{m}^{2}$ and $1175.8 \mathrm{~g} / \mathrm{m}^{2}$, respectively. In the conditions of the meadow ecotope, on the contrary, they were inferior to the original varieties by $50-65 \mathrm{~g} / \mathrm{m}^{2}$. In the ecotope conditions with leached sandy chernozem, no significant differences were found between them. 
Ключевые слова: люцерна изменчивая, фитомасса, многолисточковость, $m f$-мутация.

Keywords: alfalfa, phytomass, multifolia, $m f$-mutation.

\section{Введение}

Каждому региону соответствует определенный комплекс природных условий со специфичными проявлениями как благоприятных, так и экстремальных экологических факторов. Поэтому важное значение имеет подбор культур, сортов, сортопопуляций. способных реализовывать свой продукционный потенциал в конкретных условиях экотопа, обладающих высокой адаптационной способностью и устойчивостью к различным стрессовым факторам [Чернявских, 2016; Косолапов и др., 2015; Shi Shangli et al., 2017; Shao, 2018].

Люцерна изменчивая (Medicago varia Mart.) - важнейшая кормовая культура в Белгородской области, имеет высокий биологический потенциал, полиморфную структуру популяций [Dumacheva et al., 2018; Cherniavskih, et al., 2019a, 2019b; Meng Kong et al., 2020].

Важным направлением исследований $M$. varia является изучение рецессивной генетической мутации многолисточковости ( $m f$-мутации). Мутация контролируется рецессивным геном $(m j)$ и еще двумя генами, влияющими на ее проявление. На современном этапе селекционной работы исследования $m f$-мутаций занимают особое место. Многолисточковые формы активно изучаются и позиционируются как источники ценного материала для селекции высококачественной культурной люцерны [Petkova, 2010; Думачева, Чернявских, 2014; Рopescu et al., 2016].

Имеются данные, что растения с $m f$-мутацией обладают устойчивостью к стрессовым факторам, имеют хорошую облиственность, отличаются высокими показателями качества фитомассы на фоне снижения содержания антипитательных веществ (сапонинов) и повышения продуктивности [Streltsina et al., 2001; Bissinger et al., 2016; Chen et al., 2017; Бородаева, 2019]. Особи люцерны с высокой экспрессией $m f$-мутации рассматриваются как важный исходный материал для селекции на адаптивность, продуктивность и качество фитомассы [Petkova, Panayotova, 2007; Dzyubenko, 2013; Odorizzi et al., 2015, 2018; Чернявских, 2016].

Цель исследований - оценка продукционного потенциала надземной фитомассы сортопопуляций $M$. varia с высокой экспрессией $m f$-мутации в сравнении с исходными популяциями в различных экотопах юга Среднерусской возвышенности.

\section{Материал и методы исследования}

Объекты исследований - искусственно созданные сортопопуляции M. varia c высокой экспрессией $m f$-мутации и их исходные популяции.

Район исследований - юг Среднерусской возвышенности в пределах Белгородской области. Главная особенность региона: высокая изрезанность территории овражнобалочной сетью с большим разнообразием почвенных разностей, обладающих отличающимися физическими, агрохимическими свойствами, потенциальным плодородием и микроклиматическими особенностями.

Климат изучаемой территории умеренно-континентальный. Главные его особенности: большая годовая амплитуда температур, сравнительно мягкая зима с частыми оттепелями и снегопадами; солнечное, продолжительное лето; умеренное и не вполне устойчивое увлажнение с преобладанием летних осадков. Климатические условия региона разнообразны. Продолжительность солнечного сияния - около 1800 часов,

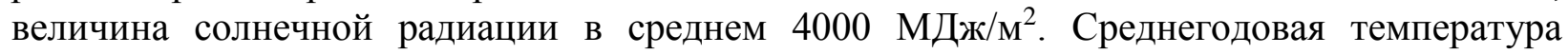
воздуха колеблется от $5.4^{\circ} \mathrm{C}$ до $6.7^{\circ} \mathrm{C}$. Средняя летняя температура увеличивается в юговосточном направлении от $18.4^{\circ} \mathrm{C}$ до $19.6^{\circ} \mathrm{C}$. Средняя зимняя температура понижается от $6.5^{\circ} \mathrm{C}$ на юге до $-8.0^{\circ} \mathrm{C}$ - на севере. Безморозный период в среднем составляет от 157 дней 
на севере, до 154 дней на юго-востоке. Средняя влажность воздуха летом составляет 63-70\% на севере и 60-66\% на юго-востоке [Roshydromet, Russian Federation, 2014; Cherniavskih et al., 2019].

Погодные условия в период проведения исследований отличались повышенной температурой воздуха по сравнению со среднемноголетней нормой и различным количеством выпадающих осадков в течение года с явно выраженным меньшим их выпадением в вегетационный период.

Исследования проведены в 2016-2018 гг. на опытных участках Чернянского отделения ЗАО «Краснояружская зерновая компания». Опыт заложен стандартным способом. Площадь учетной делянки - $2 \mathrm{~m}^{2}$. Повторность четырехкратная. Делянки двухрядковые. Ширина междурядья 25 см.

Изучали продукционный потенциал 4-х сортопопуляций M. varia (фактор А) в условиях трех экотопов (фактор В).

Фактор А (сортопопуляция):

A1 - исходная сортопопуляция районированного сорта 'Краснояружская 1'.

А2 - исходная сортопопуляция районированного сорта 'Белгородская 86'.

А 3 - сортопопуляция К-1/10 mf, полученная путем отбора из сорта 'Краснояружская 1' форм с высокой экспрессией mf-мутации многолисточковости выше 3 баллов.

A4 - сортопопуляция Б-86/3 mf, полученная путем отбора из сорта 'Белгородская 86’ форм с экспрессией $m f$-мутации многолисточковости выше 3 баллов.

Фактор В (экотоп):

В1 - экотоп полевого севооборота: Содержание гумуса - $5.1 \%$, содержание легкогидролизуемого азота - 182 мг/кг, содержание $\mathrm{P}_{2} \mathrm{O}_{5}-235$ мг/кг, $\mathrm{K}_{2} \mathrm{O}-292$ мг/кг по Чирикову в модификации ЦИНАО (ГОСТ 26204-84), $\mathrm{pH}_{\text {сол }}-6.5$.

В2 - экотоп луга: почва лугово-глеевая легкосуглинистая среднегумусная на аллювиальном суглинке (лугово-глеевая легкосуглинистая), на распаханном лугу в пойме р. Оскол. Содержание гумуса - $2.9 \%$, содержание легкогидролизуемого азота - 119 мг/кг, содержание $\mathrm{P}_{2} \mathrm{O}_{5}-88$ мг/кг, $\mathrm{K}_{2} \mathrm{O}-81 \mathrm{мг} /$ кг по Чирикову в модификации ЦИНАО (ГОСТ 26204-84) $\mathrm{pH}_{\text {сол }}-5.4$.

В3 - экотоп прифермского севооборота: почва чернозем выщелоченный среднемощный слабогумусированный супесчаный на легком карбонатном суглинке (чернозем выщелоченный супесчаный), в прифермском севообороте. Содержание гумуса $1.9 \%$, содержание легкогидролизуемого азота - 84 мг/кг, содержание $\mathrm{P}_{2} \mathrm{O}_{5}-159$ мг/кг, $\mathrm{K}_{2} \mathrm{O}-$ 140 мг/кг по Чирикову в модификации ЦИНАО (ГОСТ 26204-84), $\mathrm{pH}_{\text {сол }}-6,3$.

Исследования проводили стандартными методами. Экспрессию $m f$-мутации - по Шеффер [Sheaffer et al., 1995]. Оценку продуктивности надземной фитомассы поделяночно методом укосов в 3-х кратной повторности. Отбирали пробы для определения содержания сухого вещества. Результаты исследований статистически обработаны [Методика опытов на сенокосах ..., 1973; Доспехов, 1985; Notov et al., 2013].

\section{Результаты и их обсуждение}

Экологические условия юга Среднерусской возвышенности дают возможность получать до трех укосов фитомассы в течение вегетационного периода. В связи с этим режим изъятия фитомассы, т. е. скашивания, должен обеспечивать многоукосное и многолетнее использование ее посевов. Однако основная продуктивность надземной фитомассы люцерны формируется в большинстве случаев в 1-ом и во 2-ом укосах [Чернявских, 2009; Писковацкий, 2012]. Поэтому в работе особое внимание уделили как оценке продуктивности надземной фитомассы в 1 и 2 укосах, так и в целом за период вегетации. Анализ продуктивности по укосам имеет большое значение для оценки хозяйственной ценности сортопопуляций. Наиболее ценной, с селекционной точки зрения, является оценка продуктивности фитомассы по каждому из укосов. Это связано с тем, что 
в регионе фитопродуктивность сельскохозяйственных культур, помимо условий экотопа, в значительной степени зависит от количества осадков, выпадающих в критические фазы развития растений. Именно этот фактор часто имеет решающее значение в зонах неустойчивого увлажнения, к которым относится юг Среднерусской возвышенности [Cherniavskih et al., 2019 a].

В результате проведенных исследований максимальное значение продуктивности фитомассы в 1-ом и 2-ом укосах у всех сортопопуляций была установлена на 2-й год вегетации.

Фитопродуктивность сортопопуляций в 1-м укосе, полученная в условиях экотопа полевого севооборота, превышала показатели экотопа луга на $39.1 \%$ и экотопа прифермского севооборота на 29.7 \% (см. рисунок).

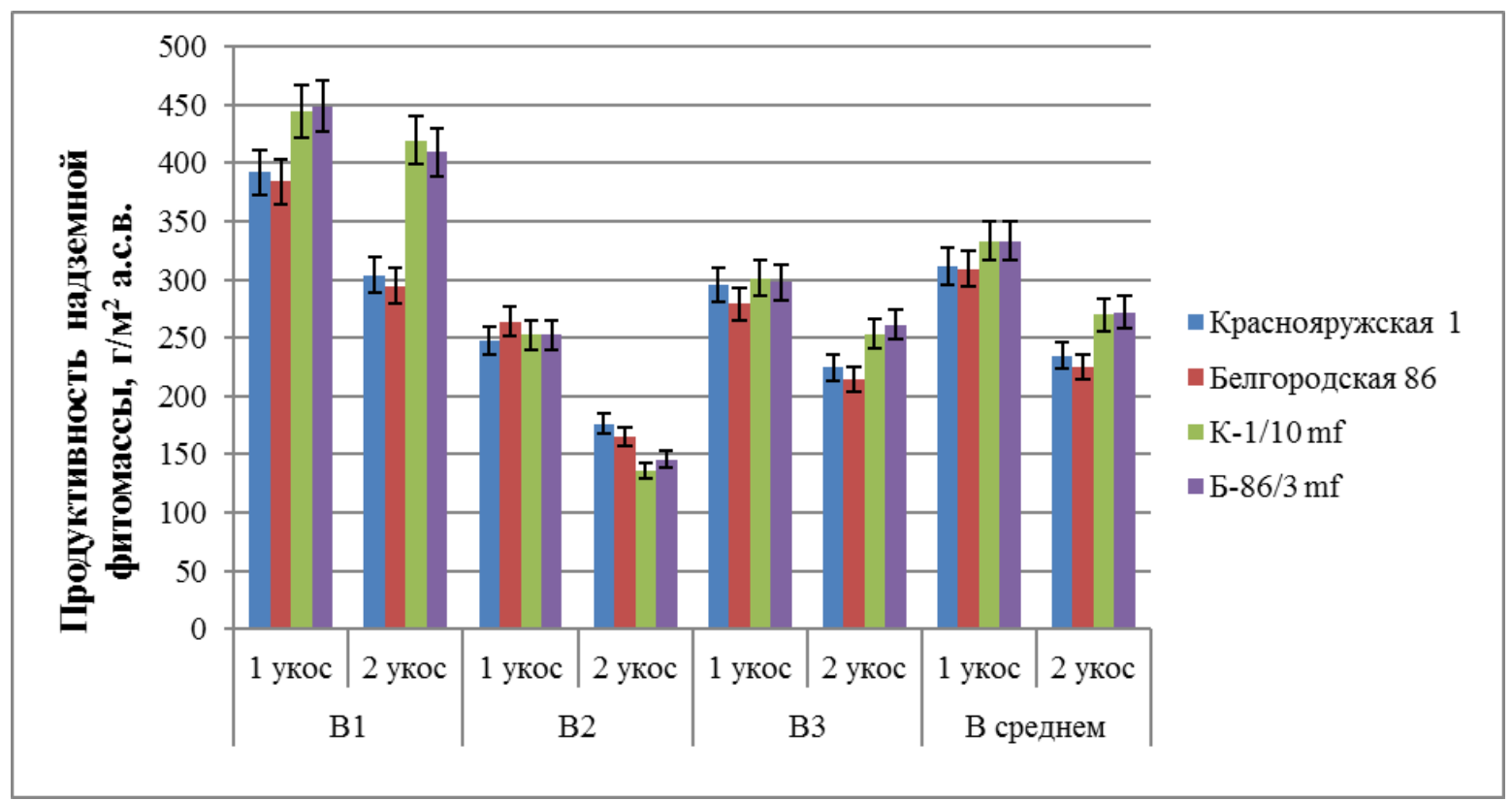

Рис. Продуктивность надземной фитомассы сортопопуляций люцерны 1-го и 2-го укосов в различных экотопах (2016-2018 гг.), г/м² а.с.в. (Примечание: В 1 - экотоп полевого севооборота, В 2 - экотоп луга;

В 3 - экотоп прифермского севооборота)

Fig. Productivity of aboveground phytomass of breeding samples of variable alfalfa in the 1st and 2nd mowing on different soil differences (2016-2018), g/m2 a. s. V.

(Note: B 1 - ecotope of field crop rotation, B 2 - meadow ecotope;

B 3 - ecotope of the near-farm crop rotation)

Продуктивность 1-го укоса у всех сортопопуляций превышала продуктивность 2-го укоса в среднем на $18.3-27.2 \%$.

В экотопах полевого севооборота у исходных сортопопуляций - сортов 'Краснояружская 1' и 'Белгородская 86' фитомасса в 1-м укосе была выше, чем во 2-м укосе на 22.5 и $23.2 \%(\mathrm{Cv}=26.2 \%)$, в то время как у образцов с высокой экспрессией $m f$-мутации (К-1/10 mf и Б-86/3 mf) отличия по укосам были незначительными (5.6-8.8 \%) $(\mathrm{Cv}=12.5 \%)$.

В условиях экотопа луга у всех сортопопуляций в 1-м укосе величина надземной фитомассы была близка по своему значению и превышала продуктивность 2-го укоса на 28.8-46.1 \%. При этом общая фитопродуктивность была на уровне $309.2-333.1$ г/м² а.с.в. минимальной в сравнении с другими исследованными экотопами.

В условиях экотопа прифермского севооборота у всех сортопопуляций отличия по продуктивности между укосами находились в пределах 12.2-23.9 \% ( $\mathrm{Cv}=14.7 \%)$. 
Для понимания процессов формирования надземной фитомассы в течение вегетационного периода у различных сортопопуляций $M$. varia провели оценку сухого вещества во всех изученных экотопах в среднем за три года исследований (см. таблицу).

Таблица

Table

Продуктивность надземной фитомассы сортопопуляций $M$. varia в различных экотопах (2016-2018 гг.), г/м² а.с.в.

Productivity of aboveground phytomass of breeding samples of $M$. varia at different soil differences (2016-2018), g/m² a. s. v.

\begin{tabular}{|l|c|c|c|c|c|}
\hline \multirow{2}{*}{$\begin{array}{c}\text { Сортопопуляция } \\
\text { (фактор А) }\end{array}$} & \multicolumn{3}{c|}{ Экотоп (фактор В)* } & \multirow{2}{*}{ В среднем } & $\begin{array}{c}\text { НСР } 05 \\
\text { (фактор В) }\end{array}$ \\
\cline { 2 - 6 } & $\mathrm{B} 1$ & $\mathrm{~B} 2$ & $\mathrm{~B} 3$ & & 14.7 \\
\hline ‘Краснояружская 1' & 974.1 & 445.7 & 649.0 & 689.6 & 15.7 \\
\hline ‘Белгородская 86’ & 929.5 & 454.6 & 606.2 & 663.4 & 16.0 \\
\hline К-1/10 mf & 1209.7 & 394.2 & 610.2 & 738.0 & 16.0 \\
\hline Б-86/3 mf & 1175.7 & 405.0 & 616.1 & 732.3 & - \\
\hline В среднем & 1072.3 & 424.9 & 620.4 & 705.8 & - \\
\hline
\end{tabular}

*Примечание: В 1 - экотоп полевого севооборота, В 2 - экотоп луга; В 3 - экотоп прифермского севооборота.

Note: B 1 - ecotope of field crop rotation, B 2 - meadow ecotope; B 3 - ecotope of the near-farm crop rotation.

Установлено, что наибольшая надземная продуктивность сухого вещества формируется у сортопопуляций люцерны изменчивой в экотопе полевого севооборота - в среднем 1072.3 г $/ \mathrm{M}^{2}$. В экотопах луга и прифермского севооборота фитопродуктивность снижается на $42.1 \%$ и $60.3 \%$ соответственно

Высокую продуктивность надземной фитомассы в экотопе полевого севооборота обеспечивают особи сортопопуляций с высокой экспрессией $m f$-мутации - К-1/10 $m f\left(1209.7 \Gamma / \mathrm{M}^{2}\right)$, Б-86/3 $m f\left(1175.8\right.$ г $\left./ \mathrm{M}^{2}\right)$.

Минимальными показателями формирования надземной фитомассы характеризуются все сортопопуляции в условиях экотопа луга $\left(394.2-454.6\right.$ г $\left./ \mathrm{m}^{2}\right)$.

При этом у сортопопуляций с высокой выраженностью экспрессии $m f$-мутации фитопродуктивность была значительно выше в экотопе полевого севооборота, чем у исходных популяций. В условиях экотопа луга, наоборот, они уступали исходным

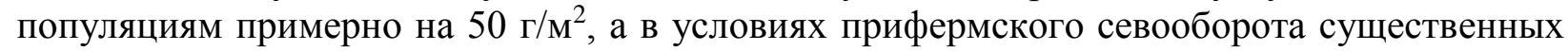
отличий не выявлено.

\section{Заключение}

Исходные популяции M. varia, которые являются высокоинтенсивными сортами ('Краснояружская 1' и 'Белгородская 86'), формируют максимальную надземную продуктивность в условиях экотопа полевого севооборота и снижают свои показатели в экотопах луга (налугово-глеевой легкосуглинистой почве) и прифермского севооборота (на черноземе выщелоченном супесчаном).

Искусственные сортопопуляции с высокой экспрессией $m f$-мутации (К-1/10 $m f$ и Б-86/3 mf) по продуктивности надземной фитомассы в экотопе полевого севооборота значительно превышают исходные сортопопуляции. В неблагоприятных условиях экотопа луга они значительно уступают по продуктивности исходным популяциям.

Наименее благоприятными для формирования надземной продуктивности для всех изученных сортопопуляций были условия экотопа прифермского севооборота. 


\section{Список литературы}

1. Бородаева Ж.А. 2019. Изучение морфометрических показателей семенной продуктивности Medicago varia Mart. с mf-мутацией в различных экотопах юга Среднерусской возвышенности. Полевой журнал биолога, 1 (3): 123-130.

2. Думачева Е.В., Чернявских В.И. 2014. Влияние способа возделывания люцерны гибридной на семенную продуктивность потомства первого поколения на карбонатных почвах ЦЧР. Кормопроизводство, 2: 23-26.

3. Доспехов Б.А. 1985. Методика полевого опыта: (с основами статистической обработки результатов исследований). М., Колос, 352 .

4. Косолапов В.М., Пилипко С.В., Костенко С.И. 2015. Новые сорта кормовых культур залог успешного развития кормопроизводства. Достижения науки и техники АПК, 4: 35-37.

5. Методика опытов на сенокосах и пастбищах. 1973. М., ВНИИК им. В.Р. Вильямса, 229 с.

6. Писковацкий Ю.М. 2012. Люцерна для многовидовых агрофитоценозов. Кормопроизводство, 11: 25-26.

7. Чернявских В.И. 2009. Эффективность возделывания бобовых и злаковых трав на склоновых землях юго-запада ЦЧЗ. Земледелие, 6: 18-19.

8. Чернявских В.И. 2016. Рекуррентная селекция как основа повышения продуктивности люцерны в Центрально-Черноземном регионе. Кормопроизводство, 12: 40-44.

9. Bissinger R., Modicano P., Alzoubi K., Honisch S., Abed M., Lang F., Faggio C. 2014. Effect of saponin on erythrocytes. International Journal of Hematology, 100 (1): 51-59.

10. Chen Y., Liu Y., Xu J., Xie Y., Zheng Q., Yue P., Yang M. 2017. A natural triterpenoid saponin as multifunctional stabilizer for drug nanosuspension powder. AAPS PharmSciTech, 18 (7): 2744-2753.

11. Cherniavskih V.I., Dumacheva E.V., Lisetskii F.N., Tsugkiev B.G., Gagieva L.Ch. 2019 a. Floral variety of Fabaceae Lindl. family in gully ecosystems in the south-west of the Central Russian Upland. Bioscience Biotechnology Research Communications, 12 (2): 203-210.

13. Cherniavskih V.I., Dumacheva E.V., Borodaeva Z.A., Gorbacheva A.A., Horolskaya E.N., Kotsareva N.V., Korolkova S.V., Gagieva L.C. 2019 b. Features of intra population variability of Medicago varia Mart. with the expressed mf-mutation on a complex qualitative characteristic. EurAsian Journal of BioSciences, 13 (2): 733-737.

14. Dumacheva E.V., Cherniavskih V.I., Gorbacheva A.A., Vorobyova O.V., Borodaeva Z.A., Bespalova E.N. Ermakova L.R. 2018. Biological resources of the Fabaceae family in the cretaceous south of Russia as a source of starting material for drought-resistance selection. International Journal of Green Pharmacy, 12 (2): 354.

15. Dzyubenko N.I. 2013. Genetic Resources for Plant Breeding: Past, Present and Future. In: International Plant Breeding Congress (Antalya, Turkey, 10-14 November 2013). Plant Breeders SubUnion of Turkey (BİSAB), Dr Vehbi ESER: 77.

16. Meng Kong, Jing Kang, Cheng-Long Han, Yan-Jie Gu, Kadambot H.M Siddique, Feng-Min Li. 2020. Nitrogen, Phosphorus, and Potassium Resorption Responses of Alfalfa to Increasing Soil Water and P Availability. Semi-Arid Environment Agronomy, 10 (2): 310.

17. Notov A.A., Dementieva S.M., Meysurova A.F. 2013. Methodical Aspects Of Comprehensive Biomonitoring. European Researcher, 11-2 (63): 2688-2699.

18. Odorizzi A., Mamani E.M.C., Sipowicz P., Julier B., Gieco J., Basigalup D. 2015. Effect of phenotypic recurrent selection on genetic diversity of non-dormant multifoliolate lucerne (Medicago sativa L.) populations. Crop and Pasture Science, 66 (11): 1190-1196.

19. Odorizzi A.S., Arolfo V., Basigalup D. 2018. A very non-dormant alfalfa (Medicago sativa L.) with high multifoliolate expression. 27 IN Proceedings. Second World Alfalfa Congress (Cordoba, Argentina, 11-14 November, 2018). Instituto Nacional de Tecnología Agropecuaria (INTA), http://www.worldalfalfacongress.org/

20. Petkova D., Panayotova G. 2007. Comparative study of trifoliolate and multifoliolate alfalfa (Medicago sativa L.) synthetic populations. Bulgarian Journal of Agricultural Science, 13: 221-224.

21. Petkova D. 2010. Multifoliate Alfalfa line with 23-24 leaves on a leaf stalk. Journal of Crop and Weed, 6 (1): 1-5.

22. Popescu S., Boldura O.-M., Ciulca S., 2016. Evaluation of the genetic variability correlated with multileaflet trait in alfalfa. Agro Life Scientific Journal, 5 (2): 125-130. 
23. Roshydromet, Russian Federation. 2014. The second evaluation report on climate changes and their effects on the territory of the Russian Federation. Moscow, The Federal service for hydrometeorology and environmental monitoring Publ. 58. URL: http://downloads.igce.ru/publications/OD_2_2014/v2014/pdf/resume_ob_eng.pdf / (available at 28 February 2019)

24. Shao J. 2018. Ideal Alfalfa Variety - Discussion on the Breeding Direction of Alfalfa in China. In: Second World Alfalfa Congress (Cordoba, Argentina, 11-14 November, 2018). Instituto Nacional de Tecnología Agropecuaria (INTA): 129.

25. Sheaffer C.C., McCaslin M., Volenec J.J., Cherney J.H., Johnson K.D., Woodward W.T., Viands D.R. 1995. Multifoliolate Leaf Expression (Leaves with Greater Than 3 Leaflets Leaf): 2.

26. Shi Shangli, Nan Lili, Smith Kevin F. 2017. The Current Status, Problems, and Prospects of Alfalfa (Medicago sativa L.) Breeding in China. Agronomy, 7 (1). https://doi.org/10.3390/agronomy7010001

27. Streltsina S. A., Zhukova M. A., Chachko E. V., Dzyubenko N.I. and Konarev A.V. 2001. Comparative analysis of intra-population variability of alfalfa (Medicago sativa L.) and Eastern goat (Galega orientalis L.) by biochemical quality traits. Agricultural biology, 5: 37-47.

\section{References}

1. Borodaeva Zh.A. A study of morphometric indicators of seed productivity Medicago varia Mart. with mf-mutation in different ecotopes of the south of the Central Russian upland. Field Biologist Journal, 1 (3): 123-130. (in Russian)

2. Dumacheva E.V., Chernyavskikh V.I. 2014. The influence of the method of cultivating hybrid alfalfa on the seed productivity of the first generation offspring on carbonate soils of the Central Black Sea. Fodder Production, 2: 23-26. (in Russian)

3. Dospekhov B.A. 1985. Metodika polevogo opyta: (S osnovami statisticheskoy obrabotki rezul'tatov issledovaniy) [Field experiment technique: (With the basics of statistical processing of research results)]. Moscow, Kolos, 352.

4. Kosolapov V.M., Pilipko S.V., Kostenko S.I. 2015. New varieties of feed crops are the key to the successful development of feed production. Achievements of Science and Technology of AICis, 4: 3537. (in Russian)

5. Metodika opytov na senokosah i pastbishhah [Method of experiments on hayfields and pastures]. 1973. Moscow, VNIIK im. V.R. Vil'jamsa, 229 p.

6. Piskovatskiy Yu.M. 2012. Alfalfa for multi-species agrophytocenosis. Fodder Production, 11: 25-26. (in Russian)

7. Chernyavskikh V.I. 2009. The efficiency of cultivation of bean and cereal grasses on the slope areas in southwest of Central Chernozem Zone. Zemledelie, 6: 18-19. (in Russian)

8. Cherniavskih V.I. 2016. Recursive selection as the basis for increasing alfalfa productivity in the Central Black Earth Region. Fodder Production, 12: 40-44. (in Russian)

9. Bissinger R., Modicano P., Alzoubi K., Honisch S., Abed M., Lang F., Faggio C. 2014. Effect of saponin on erythrocytes. International Journal of Hematology, 100 (1): 51-59.

10. Chen Y., Liu Y., Xu J., Xie Y., Zheng Q., Yue P., Yang M. 2017. A natural triterpenoid saponin as multifunctional stabilizer for drug nanosuspension powder. AAPS PharmSciTech, 18 (7): $2744-2753$.

11. Cherniavskih V.I., Dumacheva E.V., Lisetskii F.N., Tsugkiev B.G., Gagieva L.Ch. 2019 a. Floral variety of Fabaceae Lindl. family in gully ecosystems in the south-west of the Central Russian Upland. Bioscience Biotechnology Research Communications, 12 (2): 203-210.

13. Cherniavskih V.I., Dumacheva E.V., Borodaeva Z.A., Gorbacheva A.A., Horolskaya E.N., Kotsareva N.V., Korolkova S.V., Gagieva L.C. 2019 b. Features of intra population variability of Medicago varia Mart. with the expressed mf-mutation on a complex qualitative characteristic. EurAsian Journal of BioSciences, 13 (2): 733-737.

14. Dumacheva E.V., Cherniavskih V.I., Gorbacheva A.A., Vorobyova O.V., Borodaeva Z.A., Bespalova E.N. Ermakova L.R. 2018. Biological resources of the Fabaceae family in the cretaceous south of Russia as a source of starting material for drought-resistance selection. International Journal of Green Pharmacy, 12 (2): 354. 
15. Dzyubenko N.I. 2013. Genetic Resources for Plant Breeding: Past, Present and Future. In: International Plant Breeding Congress (Antalya, Turkey, 10-14 November 2013). Plant Breeders SubUnion of Turkey (BİSAB), Dr Vehbi ESER: 77.

16. Meng Kong, Jing Kang, Cheng-Long Han, Yan-Jie Gu, Kadambot H.M Siddique, Feng-Min Li. 2020. Nitrogen, Phosphorus, and Potassium Resorption Responses of Alfalfa to Increasing Soil Water and P Availability. Semi-Arid Environment Agronomy, 10 (2): 310.

17. Notov A.A., Dementieva S.M., Meysurova A.F. 2013. Methodical Aspects Of Comprehensive Biomonitoring. European Researcher, 11-2 (63): 2688-2699.

18. Odorizzi A., Mamani E.M.C., Sipowicz P., Julier B., Gieco J., Basigalup D. 2015. Effect of phenotypic recurrent selection on genetic diversity of non-dormant multifoliolate lucerne (Medicago sativa L.) populations. Crop and Pasture Science, 66 (11): 1190-1196.

19. Odorizzi A.S., Arolfo V., Basigalup D. 2018. A very non-dormant alfalfa (Medicago sativa L.) with high multifoliolate expression. 27 IN Proceedings. Second World Alfalfa Congress (Cordoba, Argentina, 11-14 November, 2018). Instituto Nacional de Tecnología Agropecuaria (INTA), http://www.worldalfalfacongress.org/

20. Petkova D., Panayotova G. 2007. Comparative study of trifoliolate and multifoliolate alfalfa (Medicago sativa L.) synthetic populations. Bulgarian Journal of Agricultural Science, 13: 221-224.

21. Petkova D. 2010. Multifoliate Alfalfa line with 23-24 leaves on a leaf stalk. Journal of Crop and Weed, 6 (1): 1-5.

22. Popescu S., Boldura O.-M., Ciulca S., 2016. Evaluation of the genetic variability correlated with multileaflet trait in alfalfa. Agro Life Scientific Journal, 5 (2): 125-130.

23. Roshydromet, Russian Federation. 2014. The second evaluation report on climate changes and their effects on the territory of the Russian Federation. Moscow, The Federal service for hydrometeorology and environmental monitoring Publ. 58. URL: http://downloads.igce.ru/publications/OD_2_2014/v2014/pdf/resume_ob_eng.pdf / (available at 28 February 2019)

24. Shao J. 2018. Ideal Alfalfa Variety - Discussion on the Breeding Direction of Alfalfa in China. In: Second World Alfalfa Congress (Cordoba, Argentina, 11-14 November, 2018). Instituto Nacional de Tecnología Agropecuaria (INTA): 129.

25. Sheaffer C.C., McCaslin M., Volenec J.J., Cherney J.H., Johnson K.D., Woodward W.T., Viands D.R. 1995. Multifoliolate Leaf Expression (Leaves with Greater Than 3 Leaflets Leaf): 2.

26. Shi Shangli, Nan Lili, Smith Kevin F. 2017. The Current Status, Problems, and Prospects of Alfalfa (Medicago sativa L.) Breeding in China. Agronomy, 7 (1). https://doi.org/10.3390/agronomy7010001

27. Streltsina S. A., Zhukova M. A., Chachko E. V., Dzyubenko N.I. and Konarev A.V. 2001. Comparative analysis of intra-population variability of alfalfa (Medicago sativa L.) and Eastern goat (Galega orientalis L.) by biochemical quality traits. Agricultural biology, 5: 37-47.

Поступила в редакиию 08.09.2020

\section{Ссылка для цитирования статьи \\ For citation}

Бородаева Ж.А., Чернявских В.И. 2020. Реализация продукционного потенциала сортопопуляций Medicago varia Mart. в различных экотопах юга Среднерусской возвышенности. Полевой журнал биолога, 2 (3): 242-249. DOI 10.18413/2658-3453-2020-2-3-242-249

Borodaeva Zh.A., Cherniavskih V.I. 2020. Implementation of the Bioresource Potential of Some Varieties of Medicago varia Mart. in Various Ecotopes of the South of the Central Russian Upland. Field Biologist Journal, 2 (3): 242-249. DOI 10.18413/2658-3453-2020-2-3-242-249 